
Em cena

\author{
J. Guinsburg
}

releitura dos textos dramáticos como procedimento em voga, não de reapresentações ou de recriações tradicionais, mas, tentativamente, de verdadeiras criaçôes cênicas, no sentido lato da expressão, vem marcando a produção teatral da última década, pelo menos em São Paulo, para não dizer no Brasil. Os fatores que propulsionam essa tendência são vários, englobando incitações culturais, sociais e políticas, e não se reduzem apenas às buscas e aos propósitos de auto-expressão dos grupos, seja na pauta de seus encenadores, seja na de seus autores, atores ou de outros actantes dos coletivos como um todo. O fenômeno se relaciona evidentemente não só com a falta de conjuntos e organizações, de algum modo institucionalizados e estáveis, que possam absorver as novas gerações, em boa parte recémegressas do crescente número de escolas e departamentos de teatro, mas também, correlata e conseqüentemente, com a nova instrumentação que os instigadores e membros de tais elencos trazem de sua formação, e dos moldes que elas assumem como estética e práticas, o que já por si as diferencia inteiramente das levas anteriores de atuantes em nossos palcos.

Este fato, sem dúvida, impele "a jovem guarda" a pesquisas e articulações que trazem a marca e a carga das "pontas de lança" dos movimentos de renovação e das vanguardas nacionais e internacionais do trabalho teatral.

Tal procedência, entretanto, nada garante por si. Numerosos são, sem dúvida, os êxitos que alcançam os caminhantes nesta trilha. Mas, à sua margem, como não poderia deixar de ser, cabe assinalar, um número não menor de equívocos. As maiores vítimas têm sido obras clássicas ou consagradas da dramaturgia que sofrem, em algumas realizaçôes, verdadeiros atentados a sua organicidade, para não dizer estupros.

Mas não é este o caso do trabalho efetuado por Isabel Teixeira, Georgette Fadel e Cibele Forjaz, que as dirigiu em: Rainha(s), cujo subtítulo fala por si do sentido perseguido, "Duas Atrizes em Busca de um Coração". Não que as três parceiras tenham dado ao seu público uma versão fiel, stricto sensu, do drama romântico de Friederich Schiller, que lhes serviu de pretextometa. Porém, ao deslocar, em boa parte, o eixo da construção dramática original e procurar infundir-lhe a presença de uma corporeidade pulsante com a vida da atualidade, nas condições e

Jacó Guinsburg é professor emérito do Departamento de Artes Cênicas e Programa de Pós-Graduação em Artes Cênicas da ECA-USP. 
com as preocupações de suas corporificadoras cênicas, ligando-a, por transplante, a um efetivo processo, não apenas stanislavskiano, de geração da personagem pela mobilização, para o imaginário, dos dados e vivências reais de seus intérpretes - ao fazê-lo com plena materialização cênica, elas souberam manter, e o que é mais importante, conseguiram revalidar teatralmente o coração palpitante da suposta peça histórica: o do embate entre duas mulheres igualmente fortes, cada uma a seu modo, de seus egos avassaladores, sob a capa da majestade real, dos interesses políticos nela envolvidos, e, na essência, no fundo, das irrecusáveis pulsões de suas feminilidades, sexualidades e de seus superego-ismos, nas formas da simbologia histórica de seu tempo.

O que vem, pois, à luz (da arena-labirinto) e é transmitido ao espectador arrastado pelas fúrias crescentes do conflito trágico, que vão submergindo os elementos cômicos postos em cena no curso da elaboração das figuras encenantes, recupera, mesmo nesta versão, o fulcro da criação schilleriana. E isto é dizer que o processo de construção das personagens, a partir do contexto da vida civil das duas atrizes, chega com toda a força dramática ao âmago de seu superobjetivo, tanto no plano da encarnação, quanto no da representação, aos olhos e ao sentimento do público.
Para concluir, vale dizer que os desempenhos de Isabel Teixeira e Georgette Fadel tornam-se tanto mais convincentes quanto, no trânsito do plano baixo de seu cotidiano para a assunção gradativa de seus papéis, conseguem levá-los ao "real" imaginário, proposto por Schiller, sem que os elementos cômicos utilizados no percurso o empanem. De grande valia nesse sentido foi a capacidade que elas tiveram de transformar, com veracidade cênica, o material dos workshops em gatilhos subjetivos das ações objetivas, até a sua explosão psicodramáti$\mathrm{ca}$ - um ajuste de contas impossível em um teatro da crueldade. É claro que esta força da apresentação brota, na relação imediata com o espectador, do trabalho das interpretes como Mary Stuart e Elisabeth da Inglaterra. Mas, é evidente também que ele não alcançaria tal integração se não fosse perceptível o sensível aporte da direção. Trata-se, com efeito, de um exemplo significativo do que pode o chamado processo colaborativo na instauração criativa de um universo cênico. De fato, o terceiro ator, ou melhor, atriz desta peça é, sem dúvida, Cibele Forjaz. Coatuante, "por trás do pano", ela movimenta, como poucos, "as luzes da ribalta" e o jogo que debaixo delas se desenrola com o ritmo, as cores e os gestos, que se gravam na platéia, como produto final atualizado desta efetiva releitura de um texto, de há muito inscrito no repertório universal. 


\section{Cego guiando cegos}

Cibele Forjaz

Prólogo:

A gênese de uma idéia e de um corpo de baile

proposta inicial desse espetáculo - a recriação da peça Mary Stuart, de Friederich Schiller, para duas atrizes - foi de Isabel Teixeira. Todos que fazem teatro sabem, entretanto, que entre uma idéia e sua realização existe a pré-produção. Ou seja, o árduo trabalho de fazer projetos e batalhar, às vezes por anos, para viabilizar os meios de produção que possibilitem o encontro entre as pessoas, que por sua vez vai desaguar na criação de um espetáculo. Isabel, com força de vontade férrea, investiu muito tempo e trabalho para transformar a sua idéia em ato. ${ }^{1}$ Como atriz-criadora-produtora, ela é a grande mãe desse projeto.

Cada um de nós, co-criadores do espetáculo, deve a ela a força-motriz que nos reuniu... Um grupo de pessoas, em sua imensa maioria mulheres, todas ligadas ao teatro de grupo e aqui reunidas em uma rede de relaçóes que tem na Cia. Livre sua origem, misturada a outras companhias: Cia São Jorge de Variedades, Grupo Bartolomeu de Depoimentos, a Barca e Cia. Nova Dança 4 - uma espécie de swing de grupos afins. Essa procedência híbrida entre a independência de um projeto de produção individual e o modo de fazer do teatro de grupo, incluindo aí a potência das relações como matriz de um processo de criação eminentemente coletiva, deu origem a Rainha[(S)].

Isabel congrega em si o pólo dessas relações contíguas, pois tem um passado em comum com Georgete Fadel. Contemporâneas da mesma escola puderam, durante os ensaios, lembrar que "eu te via nos corredores, em vestidos de época e pela fresta da porta da tua camarinha eu te guardava na minha retina... Eu já operei canhão pra você". Ambas conhecem e trabalham com Tica Lemos desde o começo de suas formaçōes. Georgete trouxe a parceria musical com Lincoln António, maturada na força de Stella do Patrocínio. Eu estou na companhia de Isabel Teixeira desde os inícios, desde a fundação da Cia. Livre, desde Toda Nudez; Um Bonde Chamado Desejo; ${ }^{2}$ Projeto Kroetz; a gravi-

Cibele Forjaz é encenadora e doutoranda do Programa de Pós-Graduação em Artes Cênicas da ECA-USP.

1 Depois de quase dois anos de tentativas, o projeto foi contemplado pelo PAC (Programa de Ação Cultural, da Secretaria de Estado da Cultura), para produção de espetáculos inéditos.

2 Quando chegou Henrique Mariano, recém saído do Teatro Oficina, o grande parceiro de Isabel na produção de Rainha[(S)]. 
dez e o nascimento de Diego; 3 a ocupação do Teatro de Arena e a direção que ela fez de todos nós no belíssimo "Arena Conta Arena: 50 Anos"; até o processo de $O$ Caminho dos Mortos, quando, de luto, ela resolveu trilhar seu próprio caminho, independente, mas presente em todas as encruzilhadas... A nossa equipe de criação vem unida da Cia. Livre, coesa e conectada em cada trabalho que compartilhamos: Simone Mina, na direção de arte, Alessandra Domingues, na luz e eu na direção, trabalhamos juntas há pelo menos dez anos. Criamos uma linguagem em comum que deu a cara de todos os nossos espetáculos: na pesquisa espacial, na relação com a platéia, no figurino-corpo, na cenografia-luz, na luz-editora, nos objetos-grávidos, nas referências, na comunicação sutil, na telepatia, no modo de fazer...

Um processo rápido, entre nós, vem carregado de muito tempo de história e pesquisa em comum. Isso faz toda a diferença.

\section{"Cego guiando cegos"}

Logo na primeira reunião, a "bomba": por razões alheias à nossa vontade o dramaturgo não poderia acompanhar os ensaios. Diante desse impasse, as atrizes, na vanguarda, propuseram que nós assumíssemos o papel do dramaturgista. A princípio, como "gato escaldado tem medo de água fria”, duvidei. Mas como minhas com- panheiras estavam tão vigorosas em sua proposta, achei que o meu papel era fortalecer a decisão que nos unia diante da dificuldade ${ }^{4}$ e seguir em frente.

Rainha[(S)] começou, então, como um processo de construção dramatúrgica a três: Isabel Teixeira, Georgete Fadel e eu. Duas atrizes e uma diretora, três mulheres de teatro e um jogo proposto: A devoração de Mary Stuart, de Friederich Schiller. O tempo para essa empreitada: três meses.

Embora o risco fosse imenso, confiamos cegamente umas nas outras e, jogando fora o bom senso, decidimos enfrentar, juntas, o desafio de escrever. Esse salto no escuro nos obrigou a ter muita fé no processo de trabalho como condutor de nossos caminhos e, já que estávamos mesmo fazendo aquilo que, sabíamos muito bem, não sabíamos fazer, nos entregamos de corpo e alma aos ensaios, sem rede de segurança.

Esta reviravolta no projeto deu a tônica do trabalho, porque colocou o próprio processo de reconstrução dramatúrgica na berlinda. Não nos cabia virarmos dramaturgas, o que não somos, mas simplesmente assumir a verdade da situação, ou seja, fortalecer os nossos papéis de atrizes e diretora, como forma mesma de escritura cênica. A construção do espetáculo, do texto e dos hipertextos foi urdida no corpo das atrizes e não no papel. $\mathrm{O}$ metateatro foi, no caso, a explicitação do nosso problema e da nossa práxis sobre ele, ação e reflexão sobre a própria ação,

Obra prima de Isabel Teixeira e Roberto Setton, um menino lindo e bem educado de 5 anos.

4 Cabe lembrar que nesse caso a experiência nos valeu em muito, porque nós três já participamos da construção de muitos espetáculos em processo colaborativo (muito antes de ganhar esse nome) e, embora nunca, até então, tenhamos escrito textos do começo ao fim, tínhamos plena consciência das dificuldades de representar este papel. O primeiro do qual participei, em 1988, já me ensinara que o ponto frágil desse trabalho é justamente a finalização dramatúrgica, o ponto forte, a alquimia do coletivo. $\mathrm{Na}$ época, há exatos vinte anos atrás, eu me prometera nunca mais entrar em um processo desses sem estar muito bem acompanhada por um(a) dramaturgo(a)... Mas como nunca deve se dizer nunca, comi minha língua e aprendi que a mesma situação pode, dependendo do contexto, ser um erro ou um acerto. A grande diferença entre uma experiência e a outra? Justamente os vinte anos de estrada entre as duas e a consciência de que "cair também não prejudica demais"... 
realizada dia a dia durante os ensaios. Nesse sentido, não havia como separar texto e cena e processo de construção do resultado. $\mathrm{O}$ nosso tema principal tornou-se, de fato, a própria devoração de Mary Stuart por duas atrizes. As atrizes-criadoras foram as primeiras personagens a entrar em cena: atrasadas, com a agenda lotada, cheias de dúvidas e contradições, que deviam ser expostas, nuas, como estávamos ao começar..

A minha função ali, principalmente no período de criação dramatúrgica, era muito clara: eu não poderia ser " $a$ " criadora do espetáculo, ou de seus conceitos fundamentais, que deveriam se urdir necessariamente em conjunto, vindos do próprio não saber, nossa maior dificuldade e, ao mesmo tempo, nossa grande riqueza potencial. Eu deveria ser, portanto, menos encenadora e mais construtora dos caminhos para a criação; mais ouvidos do que palavra; quase como uma psicanalista que não responde nada, não sabe as respostas, mas busca refletir sobre o que escuta e fazer as perguntas certas, na hora certa. Enfim, uma provocadora, cuja ação visava, principalmente, propiciar e nortear a criação das atrizes, as pitonisas do texto. A descoberta do quê nós íamos dizer com a recriação de Mary Stuart, deveria vir do próprio jogo. 5

\section{O caminho ou como devorar um clássico em pequenas partes}

O método de trabalho tomou o texto de Schiller como norte. Embora a nossa liberdade sobre o texto original tenha sido uma regra fundamental do trabalho, o respeito por ele e a necessidade de compreensão de seus temas e estrutura, também o foi. Começamos por uma análise de cada cena, suas unidades de ação, antecedentes, verbos, sub-textos, vontades e contra-vontades... Aulas de história e a leitura de várias biografias de nossas Rainhas foram complemento fundamental para esta análise de texto e as discussões que dela surgiam, adubo fértil para a criação.

A partir da análise, extraíamos os pontos essenciais e a função de cada cena no todo e, na sequiência, as atrizes improvisavam sobre ela. Depois do primeiro improviso livre, discutíamos os resultados e eu propunha a criação de um workshop. ${ }^{6}$ Fomos, portanto, pari passo com o texto original, analisando e improvisando, cena a cena.

Gravamos todos os improvisos e Isabel Teixeira fez questão de que fossem todos, sem exceção, transcritos. De modo que passamos a ter várias camadas de textos, sobre as mesmas cenas.

5 Embora o desafio da dramaturgia a três tenha levado ao paroxismo essa função da diretora-pesquisadora-provocadora, meu percurso na direção tem sido cada vez mais o de uma construtora de caminhos, no lugar da encenadora tradicional. Esse percurso não é individual, mas vem da característica coletiva dos meios de produção e da criação em grupo. Acho que essa guinada da concepção individual, realizada por um coletivo, para a concepção coletiva da cena, realizada pelos indivíduos em suas diferentes funções, é a grande mudança do ponto de vista da minha geração em relação à geração anterior (penso no caso do Brasil e, de forma mais específica, do teatro realizado na cidade de São Paulo). Embora gestada nos grupos dos anos 1960 e 1970, essa postura e função da direção ganha maturidade nos anos 1990 e se espraia no raiar do século XXI. Parece ser uma opção mais ideológica do que formal, independente das características individuais de cada diretor que trabalha em grupo.

6 Nesses workshops, os atores tornam-se criadores de uma cena, ao mesmo tempo dramaturgos, diretores e atores. Normalmente é uma idéia ou roteiro de açôes, compartilhados com os colegas e, por sua vez, também improvisados... Uma espécie de “improviso combinado". No nosso caso, essas cenas traziam, muitas vezes, cenas inteiras escritas em casa, o que não é comum. Mais um índice de que a nossa questão fundamental diante do texto original era a sua própria reescritura, para e por duas atrizes. 
Ao fim de cada semana, fazíamos um roteiro e encadeávamos as cenas e improvisos realizados até então em uma estrutura possível, um "por exemplo".7 Passávamos então para toda a equipe de trabalho um "ensaio geral” de tudo o que tínhamos construído até ali. Esses ensaios eram a medida de nossas dificuldades. Através deles tínhamos a noção de como as partes se juntavam em um todo coerente, ou não. A nossa questão fundamental era, em meio aos cacos de cenas que nós criávamos, entender que sentido dar ao todo.

Um dos primeiros improvisos - sobre a cena do primeiro ato em que Mortimer declara seu amor pela beleza sensível e, por conseguinte, à Mary Stuart - colocou a questão em cena, de forma simbólica: "Onde está meu coração?"

Essa pergunta virou, imediatamente, o nosso tema principal, a pergunta chave a ser respondida pelo processo de recriação. Para nós, ela ecoava como um guia, um super objetivo: Como colocar o nosso coração na gira? Qual o ponto fundamental a ser descoberto entre as duas rainhas do século XVI e nós? O que, das questôes colocadas no texto, nos dizem respeito diretamente e, portanto, que fio seguir, dos vários que formam a enredada trama da peça, para ser o nosso norte nessa releitura? Por que e como devorar Mary Stuart?

As respostas começaram a vir, ao mesmo tempo, de dois lados, opostos e complementares: o depoimento pessoal como tema dos improvisos e o "jogo de teatro" como estrutura de construção dramatúrgica. Essas respostas, em forma de cenas dispersas e multifacetadas, começaram a serem enredadas, em uma nova trama, que só pareceu ter algum sentido, de fato, quando colocada diante do público.

\section{A estrutura do jogo ou as razões de nossa razão}

A nossa opção, em relação à estrutura na qual tramaríamos o enredo da peça, veio como uma continuidade do meu trabalho com o teatrojogo na Cia. Livre. ${ }^{8}$ Partimos do "duelo de teatro", como a forma teatral de abordar as relações, complexas e cheias de contradições, entre as duas Rainhas. A batalha política, religiosa e amorosa entre as duas soberanas, enredadas em uma trama de muitas personagens, ganhava na cena o contorno de uma batalha de duas atrizes, enquanto constroem as suas personagens. As razôes das personagens ecoam, portanto, nas razôes das atrizes, e vice e versa.

Chegamos então à estrutura de um duelo de vida e morte, em quatro "rounds", ou atos. O que está em jogo: a vida das duas personagens, que dependem da persuasão das atrizes em relação ao público presente. $\mathrm{O}$ primeiro ato apresenta Mary Stuart e sua situação dramática - os antecedentes da ação, a prisão por vinte anos em uma torre, o tribunal de justiça e a condenação à morte, que só depende da vontade da Rainha Elizabeth para ser executada. Este primeiro ato termina com a carta de Maria pedindo um encontro com Elizabeth. O segundo ato constrói a Rainha Elizabeth e seus sentimentos contraditórios em relação à rival, expresso pela música-texto: "Só a Rainha hesita, entre a clemência e a astúcia”. Este segundo ato termina com a aquiescência de Elizabeth para encontrar-se com Maria. O terceiro é uma cena de teatro: A cena do encontro, público, entre $\mathrm{Ma}$ ria e Elizabeth, que de fato nunca aconteceu, criada por Friedrich Schiller. No fim desse ato, na hora de assinar a sentença de morte, a atriz

7 Expressão inventada por mim como paródia ao mágico "se", de Stanislavski, dado libertador de qualquer excelência ou permanência.

8 Que por sua vez encontrou ecos nas experiências de Isabel Teixeira (tanto na Cia. Livre, quanto com sua experiência na Cia. dos Atores, com a reconstrução de $A$ Gaivota, de Anton Tchécov, sob a direção de Enrique Diaz) e na pesquisa de Georgete Fadel sobre o teatro épico, na Cia. São Jorge de Variedades. 
que faz Elizabeth lava as mãos e devolve ao povo, o público do dia, a majestade. $\mathrm{O}$ ato termina com a primeira votação, onde o público escolhe qual das duas Rainhas deve morrer. O último ato propõe um segundo encontro, íntimo, inventado por nós, onde ao expôs suas razões íntimas e secretas uma para a outra as duas Rainhas mudam de posição. Neste ato, a votação, ganha contornos contraditórios, quando as atrizes propõem ao público que é possível mudar de idéia. Ao fim do segundo encontro e da segunda votação, temos um epílogo, ou seja, a contagem dos votos e a execução final. O último truque de teatro da noite se dá com o fato de que, embora a votação do público escolha a personagem que coloca a mortalha e canta a última canção de despedida, as atrizes podem, no entanto, mudar de idéia no último momento $\mathrm{e}$ inverter o jogo ao seu bel prazer, traindo a vontade soberana do "povo".

A estrutura de "jogo de teatro" de Rainha $[(S)]$ - um "duelo" entre as atrizes, que ecoa as razões das personagens e expõe epicamente a trama da peça - alvitra uma última e surpreendente "regra do jogo" para a resolução do conflito entre as duas Rainhas, na medida em que pede a participação da platéia para decidir o fim da peça, como uma obra aberta, que tem o poder de mudar o curso da História. Mas, no fim do fim, subverte a própria regra com um "truque de teatro", à revelia do jogo proposto. Este jogo dentro do jogo, que sobrepõe a vontade dos indivíduos sobre o coletivo, espelha tanto a luta interior entre as razões pessoais e as razōes de Estado, que movem a peça ${ }^{9}$, quanto questi- ona a posição de "livre arbítrio do povo", de quem emana a majestade, tanto do Rei (e da Rainha), quanto dos políticos do legislativo e do executivo, em uma democracia representativa. As regras do próprio jogo político, que parecem tão claras e indiscutíveis em uma democracia, são subvertidas quando as razões de ordem individual se sobrepõem ao bem estar do coletivo. $\mathrm{O}$ nosso voto é traído constantemente, assim como o voto da platéia, cada vez que um representante do poder público advoga em causa própria. No fim do jogo, diante do conflito entre as razões do coração e o juízo da razão, o "absurdo" se impõe.

\section{A exposição das atrizes ou as razões do nosso coração ralado}

Desde as primeiras discussões sobre as duas Rainhas, as semelhanças e, principalmente, as diferenças saltaram aos olhos. No texto de Schiller elas representam duas polaridades, duas mulheres opostas. Maria é uma Rainha sem reino, mulher, amante, mãe do futuro Rei da Inglaterra. Uma mulher linda e fascinante que sempre governou a própria vida ao sabor das emoçōes, comandada pelos homens, vítima de suas paixões e que traz em si, ao mesmo tempo, os arquétipos da puta e da santa. Elizabeth, ao contrário, embora tenha tido suas paixões secretas, ficou conhecida como a Rainha Virgem, recusou-se a casar para não ser governada e governou por quarenta anos, com mão férrea e inteligência política ímpar, levada sempre pelas ra-

9 No original, a Rainha Elizabeth assina a sentença de morte, pressionada por manifestações populares, mas, na última hora, através de um "truque de teatro" - ela entrega o documento a um "dois de paus", dando andamento a execução, sem nunca ter mandado executar com sua própria língua. - "lava as mãos" da responsabilidade pela morte de Maria e nega a própria autoria do ato final de sua personagem. O fim de Elizabeth é um anticlímax, porque ela míngua diante da própria vitória. A posição do povo na peça de Schiller também é extremamente contraditória, ora aparece como a razão final da existência de seu governante, para o bem do qual suas ações devem pender, ora como um monstro informe e desmedido que deve ser temido. 
zóes de Estado e o bem estar da Inglaterra. Ao que consta era uma trabalhadora incansável, uma workaholic do Renascimento. Schiller colocou em sua boca a famosa frase: "Eu, que julguei ter reinado como um homem, como um Rei”. Na peça de Schiller, embora as contradições de Elizabeth estejam expostas, cheias de humanidade, a opção por Maria, ao mesmo tempo vítima e heroína, é gritante. Quanto mais besteiras ela faz, mais todos os homens da peça protegem-na, admiram-na e a amam, ao contrário de Elizabeth. Passamos então a questionar as diferentes visōes sobre essas duas Rainhas e seus papéis como governantes e como mulheres, na própria peça e no decorrer do tempo. Que história era essa, de duas mulheres que reinaram no século XVI, "em tempo de homens e não de mulheres", escrita por Friedrich Schiller, homem do século XVIII, relida e representada por duas atrizes, duas mulheres guerreiras, na fronteira entre os séculos $\mathrm{XX}$ e XXI.

Assim que começamos a ensaiar, foi impossível olhar para a imagem daquelas duas mulheres de quatrocentos anos atrás, sem projetar as nossas semelhanças e diferenças, sem questionar também as nossas próprias vidas e nossos papéis de "mulheres" e "guerreiras", que vivem e trabalham num tempo em que, apesar de todas as conquistas femininas do século passado, os paradigmas continuam a ser de "um mundo de homens e não de mulheres".

Imediatamente, as nossas vidas jorraram para os improvisos e para as discussōes, os sonhos e pesadelos de uma noite, viravam cenas do dia seguinte, os nossos pais, mães, irmãs e filhos começaram a povoar o imaginário das nossas Rainhas. Suas dúvidas e contradições a ecoavam nas nossas e nossas memórias viravam os antecedentes da ação das personagens. Os depoimentos pessoais passaram a conviver com o texto de Schiller e com as cartas e discursos históricos de Mary e Elizabeth. Cruzamos os diversos tempos históricos superpostos nesse trabalho e todos eles tornaram-se diferentes planos do tempo presente, o tempo da ação teatral.
Colocamos sem pudor os nossos corações na roda, ralamos nossas emoções e pensamentos no centro da Arena. Perdemo-nos muitas vezes no labirinto de nossas histórias atravessadas. Não chegamos a nenhuma conclusão, muito menos esgotamos o assunto, tão delicado, em nossas vidas e em nosso trabalho, mas o texto construído nesse processo, "com o sangue do nosso coração ralado", é resultado de grandes transformações e questionamentos pessoais sobre os nossos papéis como mulheres e artistas, direto dessa fronteira de tempos múltiplos e histórias justapostas, para nossa realidade cotidiana, o espetáculo único de cada noite.

Como cegos guiando cegos, levados através dos tempos, pelos ventos do acaso.

\section{Epílogo ou agradecimentos especiais}

Agradeço em silêncio, no fim de cada espetáculo, às minhas parceiras nessa empreitada, pelo fato desse material múltiplo e díspar - cacos de cenas colados pelas intenções das atrizes - terem, por fim, formado um vitral que, de uma maneira ainda misteriosa para mim, comunicase com tanta fluidez com o público. De fato, durante os ensaios nos entregamos de corpo e alma ao acaso e procuramos sermos verdadeiras, inteiras, no nosso desconhecimento. Foi a nossa necessidade íntima de nos colocarmos em cheque como artistas - mulheres criadoras na fronteira entre os séculos XVI e XXI - que nos guiou. Eu nunca imaginei que a exposição do "sangue do nosso coração ralado", colhido através de um processo de trabalho no qual revelamos tanto de nossas intimidades e fraquezas umas para as outras, fosse atingir o coração do público, como veio acontecendo em todas as noites, de sexta a domingo. Tenho a certeza de que esta identificação do público com o espetáculo se deve ao grau de exposição das atrizes e a suas atuações geniais e não ao resultado final do texto, já que ele é, em si, um texto inacabado e aberto aos acontecimentos e emoçōes de cada noite. 
No fim do fim, resta fazer uma declaração de amor pelas duas atrizes com quem tive a honra de dividir minha vida durante três meses. Sinto-me ligada a elas, intimamente, por uma parceria secreta, no fundo do meu coração e por toda a minha vida..

São Paulo, quarta-feira de cinzas, 25 de fevereiro de 2009. 